\title{
The effect of dietary fat, vitamin $E$ and selenium concentrations on the fatty acid profile and oxidative stability of frozen stored broiler meat
}

\author{
P. Konieczka, M. Czauderna, A. Rozbicka-Wieczorek and S. Smulikowska ${ }^{1}$ \\ The Kielanowski Institute of Animal Physiology and Nutrition, Polish Academy of Sciences, 05-110 Jabłonna, Poland
}

KEY WORDS: rape seeds, fish oil, vitamin E, selenium, meat oxidative stability, broilers

\begin{abstract}
A total of 160 Ross 308 female broilers from day 22 to 35 of age were used to investigate the effects of vitamin $E$ and selenium (Se) supplementation on performance, fatty acid profile and oxidative stability of meat enriched with $\mathrm{n}-3$ fatty acids. There were 4 treatment groups, 3 diets contained rape seeds and fish oil (60 and $15 \mathrm{~g} \cdot \mathrm{kg}^{-1}$, respectively - RF), the control diet contained animal fat - lard. To the RF diet different doses of vitamin $\mathrm{E}$ and Se were added ( 80 and $0.3,150$ and $0.3,150$ and $0.7 \mathrm{mg}$ per kilogram of diet, respectively). Performance was measured and samples of breast and thigh meat were vacuum packed and stored at $-30^{\circ} \mathrm{C}$. The concentration of thiobarbituric acid reactive substances (TBARS) was determined after 3 weeks and after 3 months of frozen storage, when also fatty acid profiles, vitamin $E$ and cholesterol contents in meat were measured. Body weight gain and feed conversion ratio were negatively influenced $(P \leq 0.05)$ by the increased dietary level of Se. Feeding diets with rape seeds and fish oil resulted in higher concentrations and lower $\mathrm{n}-6 / \mathrm{n}-3$ PUFA ratios in breast and thigh meat $(P \leq 0.05)$ compared with the control. The increase of dietary vitamin $E$, but not Se, increased the tocopherol content in meat and reduced TBARS values in 3-month-stored thigh meat $(P \leq 0.05)$. It may be concluded that fortification of diets with vitamin $\mathrm{E}$ increases its concentration in, and oxidative stability of frozen stored breast and thigh meat, but no additional benefit was observed in feeding excess Se in combination with vitamin $\mathrm{E}$.
\end{abstract}

${ }^{1}$ Corresponding author: e-mail: s.smulikowska@ifzz.pl with the development of numerous chronic diseases. Modification of the fatty acid (FA) profile of chicken meat aimed at increasing EPA and DHA levels and decreasing the n-6/n-3 PUFA ratio may change broiler meat into a health-promoting functional food.

An efficient way of enriching poultry meat with n-3 PUFA is supplementation of diets with feed components rich in n-3 PUFA of plant or animal origin (Nguyen et al., 2003; Koreleski and 
Świątkiewicz, 2006; Rymer and Givens, 2010; Jankowski et al., 2012). When diets contain plant oils rich in $\alpha$-linolenic acid (ALA), the n-6/n-3 PUFA ratio in carcass lipids decreases substantially, but this is connected to a higher price of feed mixtures, as well as of broiler meat. Moreover, mainly ALA is deposited in the edible parts of the broiler carcass. It seems that the use of rape seeds combined with rendered fish oil can be an economically efficient way to enrich broiler meat also in EPA and DHA.

An increase in the n-3 PUFA content of broiler meat can be, nonetheless, accompanied by oxidative stress, which can adversely affect bird growth and can compromise the oxidative stability of the final product. Meat enriched with PUFA (especially n-3 PUFA) may be more prone to oxidation of lipids during storage, and, consequently the shelf-life of the final product may be shorter (Bou et al., 2009; Jankowski et al., 2012).

Several strategies have been applied to enrich chicken meat with n-3 PUFA without compromising meat oxidative stability. Increasing dietary vitamin $\mathrm{E}$ ( $\alpha$-tocopheryl acetate) or vitamin $\mathrm{E}$ and selenium (Se), which are the first line of defence against free radicals, was seen as the most efficient way of improving the oxidative stability of chicken meat during storage (Koreleski and Świątkiewicz, 2006; Perez et al., 2010). Furthermore, dietary supplementation with vitamin $\mathrm{E}$ and Se results in higher deposition of these additives in broiler meat and additionally improves its functional properties (Bou et al., 2009; Olmedilla-Alonso et al., 2013). The effects of dietary vitamin $\mathrm{E}$ and Se on the fatty acid profile of chicken tissues are rather controversial. Some authors have shown that dietary Se (Bou et al., 2005; Nyquist et al., 2013) and vitamin E (Cortinas et al., 2004; Rymer and Givens, 2010) did not influence the long chain (LC)-PUFA level in broiler meat. Others found more n-3 LC-PUFA in the meat of broilers fed a diet with a high level of Se (Haug et al., 2007; Kralik et al., 2012) or a high level of vitamin E (Surai and Sparks, 2000). Moreover, some experimental results suggested that a combination of different antioxidants may be more effective in retarding oxidation processes than the use of a single antioxidant (Bou et al., 2009).

Therefore, the objective of this study was to evaluate the effects of a diet enriched with n-3 PUFA sources as well as with vitamin $\mathrm{E}$ and $\mathrm{Se}$ on the lipid profile, vitamin $\mathrm{E}$ level and oxidative stability of chicken meat during frozen storage.

\section{Material and methods}

\section{Animals, housing, diets and experimental design}

All procedures were approved by the Local Animal Care and Ethics Committee in Warsaw (Poland).

A total of 200 feather-sexed one-day-old, Ross 308 broiler females were obtained from a local commercial hatchery, kept in electrically heated battery brooders and fed a standard starter diet for 3 weeks. On day 22 , after $4 \mathrm{~h}$ of feed deprivation, the chickens were weighed, and for every treatment, 40 birds with a body weight close to the group average were randomly allocated to 4 treatment groups and placed in individual wire-mesh cages $(36 \times 50 \times 48 \mathrm{~cm})$. From this point, each bird was treated as a replication and feed intake was individually measured. Over the entire experimental period (day 22 to 36 ), the room temperature was maintained at $22^{\circ} \mathrm{C}$ with a light cycle of $18 \mathrm{~h}$ light and $6 \mathrm{~h}$ darkness.

Four isoprotein and isoenergetic diets based on wheat, maize and soyabean meal were prepared, each as grower and finisher (Table 1). The control diet contained lard as a supplemental fat of animal origin. The fatty acid (FA) profiles of the experimental diets (RF) (Table 2) were changed by replacing lard by a similar amount of crude fat derived from rape seeds (winter 00 variety Bojan) and rendered fish oil (Agro-Fish, Kartoszyno, Poland) (Table 3). The vitamin-mineral premix added to the control and RF diets contained $80 \mathrm{mg}$ vitamin $\mathrm{E}$ and $0.3 / 0.25 \mathrm{mg}$ Se per kilogram. In the premixes added to diets RFE and RFES, the level of vitamin E was increased to $150 \mathrm{mg} \cdot \mathrm{kg}^{-1}$, in the RFES diet, also the level of Se was increased to $0.7 \mathrm{mg} \cdot \mathrm{kg}^{-1}$ by addition of selenized yeast (SelPlex 1000, Alltech, Nicholasville, KY, USA). Diets were pelleted $\left(50^{\circ} \mathrm{C}\right)$ in a CL-2 CPM laboratory pellet mill. Chickens were fed with grower diets for 1 week, then finisher diets until slaughter. Feed and water were provided ad libitum.

\section{Sampling procedures}

Feed intake and body weight were measured after $4 \mathrm{~h}$ feed deprivation and performance was calculated for the period of 22-35 days of life. On day 36 or 37 of age, all chickens were weighed and sacrificed by cervical dislocation. The liver and heart were excised and weighed. From 9 birds per group the breast and the thigh meat (without skin) were excised, chilled at $4^{\circ} \mathrm{C}$ and cut into small pieces. 
Table 1. Composition and nutritive value of grower and finisher diets, $\mathrm{g} \cdot \mathrm{kg}^{-1}$ air-dry matter

\begin{tabular}{|c|c|c|c|c|c|c|c|c|}
\hline \multirow{2}{*}{ Indices } & \multicolumn{4}{|c|}{ Grower, from $22^{\text {nd }}-28^{\text {th }}$ day } & \multicolumn{4}{|c|}{ Finisher, from $29^{\text {th }}$ day to slaughter } \\
\hline & control $_{G}$ & $\mathrm{RF}_{\mathrm{G}}$ & $\mathrm{RFE}_{G}$ & RFES $_{G}$ & control $_{\mathrm{F}}$ & $\mathrm{RF}_{\mathrm{F}}$ & $\mathrm{RFE}_{\mathrm{F}}$ & RFES $_{F}$ \\
\hline \multicolumn{9}{|l|}{ Ingredients } \\
\hline wheat & 380.14 & 368.24 & 368.1 & 367.7 & 428.5 & 416.96 & 416.82 & 416.37 \\
\hline soyabean meal & 346.9 & 323.4 & 323.4 & 323.4 & 300.2 & 276.6 & 276.6 & 276.6 \\
\hline maize & 200.0 & 200.0 & 200.0 & 200.0 & 200.0 & 200.0 & 200.0 & 200.0 \\
\hline rape seeds & - & 60.0 & 60.0 & 60.0 & - & 60.0 & 60.0 & 60.0 \\
\hline fish oil & - & 15.0 & 15.0 & 15.0 & - & 15.0 & 15.0 & 15.0 \\
\hline lard & 39.1 & - & - & - & 39.2 & - & - & - \\
\hline limestone & 10.9 & 10.9 & 10.9 & 10.9 & 10.5 & 10.4 & 10.4 & 10.4 \\
\hline mono-Ca-phosphate & 11.2 & 11.0 & 11.0 & 11.0 & 11.1 & 10.9 & 10.9 & 10.9 \\
\hline $\mathrm{NaCl}$ & 2.0 & 2.0 & 2.0 & 2.0 & 2.0 & 2.0 & 2.0 & 2.0 \\
\hline $\mathrm{NaHCO}_{3}$ & 1.0 & 1.0 & 1.0 & 1.0 & 1.0 & 1.0 & 1.0 & 1.0 \\
\hline L-Lys (78\%) & 1.6 & 1.5 & 1.5 & 1.5 & 1.0 & 0.9 & 0.9 & 0.9 \\
\hline DL-Met $(98 \%)$ & 1.8 & 1.6 & 1.6 & 1.6 & 1.3 & 1.1 & 1.1 & 1.1 \\
\hline L-Thr (98\%) & 0.3 & 0.3 & 0.3 & 0.3 & 0.1 & 0.04 & 0.04 & 0.04 \\
\hline vitamin-mineral mixture ${ }^{1,2}$ & $5.0^{1}$ & $5.0^{1}$ & $5.0^{1}$ & $5.0^{1}$ & $5.0^{2}$ & $5.0^{2}$ & $5.0^{2}$ & $5.0^{2}$ \\
\hline vitamin $\mathrm{E}^{3}$ & 0.06 & 0.06 & 0.2 & 0.2 & 0.1 & 0.1 & 0.24 & 0.24 \\
\hline Sel-Plex $1000^{4}$ & - & - & - & 0.4 & - & - & - & 0.45 \\
\hline \multicolumn{9}{|l|}{ Calculated nutrients content } \\
\hline crude protein, $\mathrm{g} \cdot \mathrm{kg}^{-1} 5$ & 215.0 & 215.0 & 215.0 & 215.0 & 200.3 & 200.3 & 200.3 & 200.3 \\
\hline $\mathrm{ME}, \mathrm{MJ} \cdot \mathrm{kg}^{-1} 5,6$ & 12.1 & 12.1 & 12.1 & 12.1 & 12.4 & 12.3 & 12.3 & 12.3 \\
\hline crude fat, $\mathrm{g} \cdot \mathrm{kg}^{-15}$ & 59.1 & 59.1 & 59.1 & 59.1 & 59.2 & 59.2 & 59.2 & 59.2 \\
\hline Se, $\mathrm{mg} \cdot \mathrm{kg}^{-17}$ & 0.30 & 0.30 & 0.30 & 0.70 & 0.25 & 0.25 & 0.25 & 0.70 \\
\hline vit. $\mathrm{E}, \mathrm{mg} \cdot \mathrm{kg}^{-1} 7$ & 80.0 & 80.0 & 150.0 & 150.0 & 80.0 & 80.0 & 150.0 & 150.0 \\
\hline
\end{tabular}

control - control diet with lard, G - grower, F - finisher, RF - diet with rape seeds and fish oil, RFE - diet with rape seeds and fish oil supplemented with a-tocopheryl acetate, RFES - diet with rape seeds and fish oil supplemented with a-tocopheryl acetate and selenium; ${ }^{1,2}$ provide per kg of diet: IU: vit. $A 10000$, vit. $D_{3} 5000$; mg: vit. $E 50$, vit. $B_{1} 2$, vit. $B_{2} 6$, biotin 0.2 , vit. $B_{6} 4$, vit. $B_{12} 0.016$, vit. $K_{3} 3$, nicotinic acid 55 , folic acid 1.75 , pantothenic acid 13, choline 300, Mn 120, Zn 100, Se 0.3, Cu 16, Fe 50, J 1, Co 0.3, coccidiostat Monteban 70; g: Ca 1.1; ${ }^{2}$ provide per kg of diet: IU: vit. $A 9000$, vit. $D_{3} 2500$; mg: vit. E 30, vit. $B_{1} 2.25$, vit. $B_{2} 4.5$, biotin 0.1 , vit. $B_{6} 3$, vit. $B_{12} 0.015$, vit. $K_{3} 2$, nicotinic acid 30 , folic acid 0.75 , pantothenic acid 9.375, choline 250, Mn 70, Zn 60, Se 0.25, Cu 6, Fe 40, J 0.6; g: Ca 1.375; both premixes contained also: endo-1,4- $\beta$-xylanase

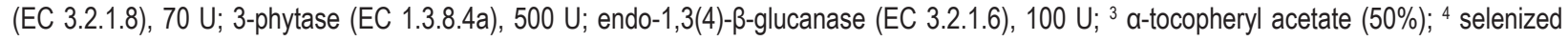
yeasts (Sel-Plex10000, Alltech, Nicholasville, KY, USA) $1 \mathrm{mg} \mathrm{Se} \cdot \mathrm{g}^{-1} ;$, 5,6 based on analyses of raw materials and table data (Smulikowska and Rutkowski, 2005, and Sauvant et al., 2004); ${ }^{7}$ supplemented

Three representative samples were prepared from the breast meat and thigh meat of each carcass. Samples were marked, vacuum packed and stored at $-30^{\circ} \mathrm{C}$. The first sample of each kind of meat was thawed after 3 weeks, homogenized and used for thiobarbituric acid reactive substances (TBARS) analysis, the second sample was thawed after 3 months and used for fatty acid, tocopherol, cholesterol and TBARS analyses.

\section{Fatty acid analysis}

The fatty acid content in meat samples was measured after 3 months of frozen storage. Prior to analysis, samples of feeds and diets were finely ground, samples of meat were thawed at $4^{\circ} \mathrm{C}$ for $12 \mathrm{~h}$ and homogenized. Samples were extracted, saponified and methylated according to the method of Czauderna et al. (2007). Analysis of fatty acid methyl ester (FAMEs) composition was performed on a Shimadzu GC-MS-QP2010 Plus EI gas chromatograph equipped with a BPX70 fused silica capillary column $(120 \mathrm{~m} \times 0.25 \mathrm{~mm}$ i.d. $\times 0.25 \mu \mathrm{m}$ film thickness), a quadrupole mass selective (MS) detector (Model 5973N) and an injection port. Helium as the carrier gas operated at a constant pressure and initial flow rate of $1 \mathrm{ml} \cdot \mathrm{min}^{-1}$. Fatty acids (as FAMEs) in meat samples were determined according to Czauderna et al. (2007).

\section{TBARS assay}

The oxidative stability of meat lipids was measured after 3 weeks and after 3 months of frozen storage. Samples of meat were thawed at $4^{\circ} \mathrm{C}$ for $24 \mathrm{~h}$ and then homogenized using a tissue homogenizer (IKA ${ }^{\circledR}$ T18 basic, Ultra-Turrax ${ }^{\circledR}$, Germany). Sample hydrolysis, saponification and derivatization 
Table 2. Fatty acid profile of the control and experimental diets, $\%$ total fatty acids

\begin{tabular}{|c|c|c|c|}
\hline \multirow[t]{2}{*}{ Fatty acids } & \multirow[t]{2}{*}{ Control $^{1}$} & \multirow{2}{*}{$\frac{\text { RF, RFE, RFES }}{\text { grower }}$} & \multirow{2}{*}{$\frac{\text { RF, RFE, RFES }}{\text { finisher }}$} \\
\hline & & & \\
\hline C14:0 & 0.7 & 0.6 & 1.4 \\
\hline C16:0 & 25.6 & 13.5 & 14.5 \\
\hline C18:0 & 8.5 & 1.5 & 1.4 \\
\hline SFA & 34.7 & 15.7 & 17.3 \\
\hline C18:1 & 38.7 & 52.8 & 52.8 \\
\hline MUFA & 40.5 & 52.2 & 53.0 \\
\hline C18:2n-6 (LA) & 23.7 & 26.2 & 24.2 \\
\hline n-6 PUFA & 23.7 & 26.2 & 24.2 \\
\hline C18:3n-3 (ALA) & 1.1 & 5.1 & 5.5 \\
\hline$\Sigma$ EPA and DHA & nd & 0.2 & 0.2 \\
\hline n-3 PUFA & 1.1 & 5.3 & 5.7 \\
\hline$n-6 / n-3$ PUFA & 21.5 & 4.9 & 4.2 \\
\hline
\end{tabular}

${ }^{1}$ mean values of grower and finisher diets containing lard as a source of supplemental fat; ${ }^{2}$ mean values of diets containing rape seeds and fish oil (see Table 1); SFA - saturated fatty acids (C14:0 + C16:0 + $\mathrm{C} 18: 0+\mathrm{C} 20: 0+\mathrm{C} 22: 0+\mathrm{C} 24: 0) ;$ MUFA - monounsaturated fatty acids (C16:1 + C17:1 + C18:1 + C20:1 + C21:1 + C22:1); n-6 PUFA - polyunsaturated fatty acids (C18:2n-6+C18:3n-6 + C20:2n-6 + C20:3n-6 + C20:4n-6 + C22:4n-6); n-3 PUFA - (C18:3n-3 + C20:5n-3 + C22:5n-3 + C22:6n-3); EPA - eicosapentaenoic acid (C20:5n-3); DHA - docosahexaenoic acid (C22:6n-3)

were done according to the protocol described by Konieczka et al. (2014). The concentration of thiobarbituric acid (TBA) derivative of malondialdehyde (MDA) was measured by using an ultra-fast-performance liquid chromatographic system (Shimadzu, Kyoto, Japan). Separations were performed on an Accucore C18-column (particle size: $2.6 \mu \mathrm{m}$; Hydro$\mathrm{RP}, 150 \times 3.0 \mathrm{~mm}$; Thermo-Scientific, Waltham, MA, USA) in conjunction with a guard column containing Accucore C18 pellicular packing material (particle size: $2.6 \mu \mathrm{m} ; 10 \times 4 \mathrm{~mm}$; Thermo-Scientific, Waltham, MA, USA). The samples were analysed using a linear binary gradient programme of acetonitrile in water (Konieczka et al., 2014). The photodiode array detector wavelength was set at $530 \mathrm{~nm}$. TBARS, expressed as milligrams of MDA per kilogram of meat, were calculated from the standard curve of MDA prepared against the background of the same type of assayed tissues to avoid a matrix effect.

\section{Determination of tocopherols and cholesterol content}

Tocopherols and cholesterol were determined in frozen meat stored for 3 months. Samples of meat were thawed at $4^{\circ} \mathrm{C}$ for $24 \mathrm{~h}$ and then homogenized using a tissue homogenizer (IKA $® T 18$ basic, UltraTurrax ${ }^{\circledR}$, Staufen, Germany). The concentration of tocopherols and cholesterol was assayed according to Czauderna et al. (2009). Analyses were done by using ultra-fast-performance liquid chromatographic equipment (Shimadzu, Kyoto, Japan). This equipment consisted of a Kinetex C18-column (particle size: $2.6 \mu \mathrm{m}$; Hydro-RP, $150 \times 2.1 \mathrm{~mm}$, Phenomenex, Torrance, CA, USA) in conjunction with a guard column containing Kinetex C18 pellicular packing material $(2.6 \mu \mathrm{m} ; 4 \times 2 \mathrm{~mm}$, Phenomenex, Torrance, CA, USA). The samples were analysed at $22^{\circ} \mathrm{C}$ using a linear binary gradient programme (Czauderna et al., 2009). The fluorescent detector wavelength was set at $295 \mathrm{~nm}$ for analysis of a $\alpha$-, $\delta$ - and $\gamma$-tocopherol and at $284 \mathrm{~nm}$ for $\alpha$-tocopherol acetate; the photodiode array detector was set at a wavelength of 193 $\mathrm{nm}$ for cholesterol and $195 \mathrm{~nm}$ for $25-\mathrm{OH}$-cholesterol detection.

\section{Calculations and statistical analysis}

Feed intake, body weight gain (BWG) and feed conversion ratio (FCR) were calculated for the period from day 22 to 35 of life. The results of performance and fatty acids composition were analysed by one-way analysis of variance (ANOVA). The effects of dietary treatments, frozen storage duration, and meat part on the TBARS concentration were analysed as a multifactorial arrangement using STATGRAPHICS ${ }^{\circledR}$ Centurion XVI ver. 16.1.03 (1982-2010). The differences between experimental groups were considered significant at a level of $P \leq 0.05$.

\section{Results}

The fatty acid profile of the supplemental fat sources is shown in Table 3. Rape seeds and fish oil contained more n-3 PUFA and had a lower n-6/n-3 PUFA ratio in comparison with lard, fish oil also contained EPA and DHA. The lipid fraction of diets with rape seeds and fish oil had a higher content of $\alpha$-linolenic acid, consequently the n-6/n-3 PUFA ratio was approximately 4-fold lower than in the control diet.

During the experiment, four birds were rejected for reasons not related to the experimental factors. The performance and the weight of the selected organs of broilers are shown in Table 4. In group RF, the BWG and FCR did not differ from the respective values in the control group, however, in groups RFE and RFES, BWG was lower by $4 \%$ and $6.5 \%$ respectively $(P \leq 0.05)$. In group RFES the FCR was worse than in the control group by $3 \%(P \leq 0.05)$. The weight of the liver was similar, whereas the weight of the heart was higher in groups RFE and RFES in comparison with the control group $(P \leq 0.05)$.

The fatty acid profiles of breast and thigh lipids measured after 3 months storage in a freezer are shown in Tables 5 and 6 . In breast meat of chickens 
Table 3. Fatty acid profile of supplemental fat sources used in the diets, $\%$ total fatty acids

\begin{tabular}{|c|c|c|c|}
\hline \multirow{2}{*}{ Fatty acid } & \multicolumn{3}{|c|}{ Fat source } \\
\hline & lard & rape seeds & fish oil \\
\hline $\mathrm{C} 14: 0$ & 1.1 & 0.1 & 2.9 \\
\hline $\mathrm{C} 16: 0$ & 18.3 & 2.3 & 10.9 \\
\hline C18:0 & 6.9 & 0.5 & 1.7 \\
\hline SFA & 26.8 & 2.9 & 15.8 \\
\hline C16:1 & 3.8 & 0.2 & 5.1 \\
\hline C18:1 & 55.4 & 58.6 & 45.2 \\
\hline MUFA & 59.7 & 59.5 & 64.3 \\
\hline C18:2n-6 (LA) & 12.5 & 28.0 & 10.2 \\
\hline C20:4n-6 (AA) & 0.1 & 0.03 & 0.2 \\
\hline $\mathrm{n}-6$ PUFA & 12.8 & 28.0 & 11.0 \\
\hline C18:3n-3 (ALA) & 0.6 & 9.6 & 5.0 \\
\hline$\sum$ EPA and DHA & 0.03 & nd & 3.65 \\
\hline$n-3$ PUFA & 0.7 & 9.6 & 8.9 \\
\hline$n-6 / n-3$ PUFA & 18.2 & 2.9 & 1.2 \\
\hline
\end{tabular}

SFA, MUFA, n-6 PUFA, n-3 PUFA, EPA, DHA see Table 2; nd - not detected

Table 4. Effects of dietary treatments on performance (from $22^{\text {nd }}$ to $35^{\text {th }}$ day) and weight of heart and liver at day 36 or 37

\begin{tabular}{|c|c|c|c|c|c|}
\hline \multirow{2}{*}{ Indices } & \multicolumn{4}{|c|}{ Dietary treatments } & \multirow{2}{*}{ SEM } \\
\hline & control & RF & RFE & RFES & \\
\hline Initial BW, kg1 & 0.99 & 0.99 & 0.99 & 0.99 & 0.008 \\
\hline Final BW, $\mathrm{kg}^{2}$ & $2.35^{\mathrm{c}}$ & $2.32^{\mathrm{bc}}$ & $2.29^{a b}$ & $2.26^{\mathrm{a}}$ & 0.024 \\
\hline BWG, kg & $1.36^{c}$ & $1.33^{b c}$ & $1.30^{\mathrm{ab}}$ & $1.27^{\mathrm{a}}$ & 0.020 \\
\hline Feed intake, kg & 1.99 & 1.95 & 1.92 & 1.93 & 0.026 \\
\hline $\mathrm{FCR}$, $\mathrm{kg}$ feed $\cdot \mathrm{kg}^{-1} \mathrm{BWG}$ & $1.47^{\mathrm{a}}$ & $1.47^{\mathrm{a}}$ & $1.48^{\mathrm{a}}$ & $1.52^{\mathrm{b}}$ & 0.011 \\
\hline Heart, $g \cdot 100 g^{-1}$ LBW & $0.41^{\mathrm{a}}$ & $0.43^{\mathrm{ab}}$ & $0.44^{b}$ & $0.44^{b}$ & 0.008 \\
\hline Liver, $\mathrm{g} \cdot 100 \mathrm{~g}^{-1} \mathrm{LBW}$ & 2.21 & 2.26 & 2.18 & 2.33 & 0.045 \\
\hline \multicolumn{6}{|c|}{$\begin{array}{l}\text { control, RF, RFE, RFES see Table } 1 ;{ }^{1} \text { at } 22^{\text {nd }} \text { day of life; }{ }^{2} \text { at } 35^{\text {th }} \text { day of } \\
\text { life; BW - body weight, BWG - body weight gain, FCR - feed conversion } \\
\text { ratio, LBW - live body weight; ab means with different superscipts within } \\
\text { a row are significantly different at } P \leq 0.05\end{array}$} \\
\hline
\end{tabular}

from the experimental groups, the share of SFA was lower, whereas the share of MUFA was higher in comparison with the control group, but only in groups RFE and RFES $(P \leq 0.05)$. In thigh meat the differences were not significant. Both breast and thigh meat from the experimental groups contained a higher level of n-3 PUFA in comparison with the control group. In group RF the level of n-6 PUFA was higher in breast meat and similar in thigh meat, whereas in both tissues it was lower in groups RFE and RFES in comparison with the control. In both breast and thigh meat the n-6/n-3 PUFA ratio was lower $(P \leq 0.05)$ in comparison with the respective meat from the control group.

The concentration of different forms of tocopherols, cholesterol and 25-OH-cholesterol in breast and thigh meat measured after 3 months frozen storage is shown in Table 7. In breast and thigh meat, the $\alpha$-tocopherol concentration was higher in groups
Table 5. Fatty acid profile of breast meat lipids, $\%$ of total fatty acids, after 3-months storage in a freezer

\begin{tabular}{lccccc}
\hline \multirow{2}{*}{ Fatty acids } & \multicolumn{2}{c}{ Dietary treatments } & \multirow{2}{*}{ SEM } \\
\cline { 2 - 5 } & control & RF & RFE & RFES & \\
\hline SFA & $36.81^{\mathrm{b}}$ & $31.65^{\mathrm{a}}$ & $30.39^{\mathrm{a}}$ & $29.51^{\mathrm{a}}$ & 1.395 \\
MUFA & $52.97^{\mathrm{a}}$ & $54.68^{\mathrm{a}}$ & $59.48^{\mathrm{b}}$ & $60.38^{\mathrm{b}}$ & 1.527 \\
PUFA & $10.22^{\mathrm{a}}$ & $13.68^{\mathrm{b}}$ & $10.12^{\mathrm{a}}$ & $10.11^{\mathrm{a}}$ & 0.215 \\
C18:2n-6 (LA) & $7.65^{\mathrm{b}}$ & $8.60^{\mathrm{c}}$ & $5.48^{\mathrm{a}}$ & $5.31^{\mathrm{a}}$ & 0.082 \\
C20:4n-6 (AA) & 1.74 & 2.29 & 2.00 & 1.49 & 0.227 \\
n-6 PUFA & $9.74^{\mathrm{b}}$ & $11.20^{\mathrm{c}}$ & $7.64^{\mathrm{a}}$ & $6.84^{\mathrm{a}}$ & 0.398 \\
C18:3n-3 (ALA) & $0.35^{\mathrm{a}}$ & $1.15^{\mathrm{b}}$ & $1.28^{\mathrm{b}}$ & $2.04^{\mathrm{c}}$ & 0.213 \\
C20:5n-3 (EPA) & trace & 0.28 & 0.38 & 0.46 & 0.07 \\
C22:5n-3 (DPA) & $0.12^{\mathrm{a}}$ & $0.46^{\mathrm{b}}$ & $0.40^{\mathrm{b}}$ & $0.36^{\mathrm{b}}$ & 0.057 \\
C22:6n-3 (DHA) & trace $^{\mathrm{a}}$ & $0.58^{\mathrm{b}}$ & $0.42^{\mathrm{a}}$ & $0.42^{\mathrm{a}}$ & 0.048 \\
n-3 PUFA & $0.51^{\mathrm{a}}$ & $2.48^{\mathrm{b}}$ & $2.48^{\mathrm{b}}$ & $3.27^{\mathrm{c}}$ & 0.215 \\
IEPA and DHA & trace & 0.87 & 0.81 & 0.87 & 0.102 \\
n-6/n-3 PUFA & $18.58^{\mathrm{b}}$ & $4.62^{\mathrm{a}}$ & $3.10^{\mathrm{a}}$ & $2.22^{\mathrm{a}}$ & 0.403 \\
\hline
\end{tabular}

control, RF, RFE, RFES see Table 1; SFA, MUFA, PUFA, EPA, DHA see Table 2; ${ }^{\text {ab }}$ means with different superscipts within a row are significantly different at $P \leq 0.05$

Table 6. Fatty acid profile of thigh meat lipids, $\%$ of total fatty acids, after 3-months storage in a freezer

\begin{tabular}{|c|c|c|c|c|c|}
\hline \multirow{2}{*}{ Fatty acids } & \multicolumn{4}{|c|}{ Dietary treatments } & \multirow{2}{*}{ SEM } \\
\hline & control & $\mathrm{RF}$ & RFE & RFES & \\
\hline$\overline{\text { SFA }}$ & 34.66 & 33.57 & 33.99 & 31.84 & 0.754 \\
\hline MUFA & 55.08 & 53.58 & 56.34 & 59.97 & 1.721 \\
\hline PUFA & 10.26 & 12.85 & 9.67 & 8.19 & 0.726 \\
\hline C18:2n-6 (LA) & $6.83^{b}$ & $6.72^{b}$ & $4.64^{\mathrm{a}}$ & $4.22^{\mathrm{a}}$ & 0.555 \\
\hline C20:4n-6 (AA) & 2.79 & 3.09 & 3.06 & 1.89 & 0.330 \\
\hline n-6 PUFA & $9.85^{b}$ & $10.10^{b}$ & $7.70^{\mathrm{a}}$ & $6.11^{\mathrm{a}}$ & 0.744 \\
\hline C18:3n-3 (ALA) & $0.31^{\mathrm{a}}$ & $1.65^{c}$ & $0.93^{b}$ & $1.08^{b c}$ & 0.188 \\
\hline C20:5n-3 (EPA) & trace & $0.32^{\mathrm{ab}}$ & $0.53^{b}$ & $0.28^{a}$ & 0.053 \\
\hline $\mathrm{C} 22: 5 n-3$ (DPA) & $0.10^{\mathrm{a}}$ & $0.36^{b}$ & $0.43^{b}$ & $0.35^{b}$ & 0.045 \\
\hline C22:6n-3 (DHA) & trace & 0.42 & 0.43 & 0.38 & 0.042 \\
\hline n-3 PUFA & $0.41^{a}$ & $2.75^{c}$ & $1.97^{b}$ & $2.08^{b}$ & 0.178 \\
\hline$\sum E P A$ and DHA & trace & 0.74 & 0.61 & 0.65 & 0.100 \\
\hline n-6/n-3 PUFA & $24.55^{b}$ & $3.81^{\mathrm{a}}$ & $3.57^{\mathrm{a}}$ & $3.00^{\mathrm{a}}$ & 2.089 \\
\hline
\end{tabular}

control, RF, RFE, RFES see Table 1; SFA, MUFA, PUFA, EPA, DHA see Table 2; ab means with different superscipts within a row are significantly different at $P \leq 0.05$

RFE and RFES in comparison with both the control and RF groups $(P \leq 0.05)$. In breast meat, the $\gamma$-tocopherol concentration was greater in group RF in comparison with the control and further increased in group RFE. However, in group RFES it did not differ from that in groups RF and RFE. In thigh meat, the $\gamma$-tocopherol concentration was lowest in group RF, whereas vitamin $\mathrm{E}$ supplementation with or without Se restored it to a level similar to that in the control group. In breast meat, no difference among the examined groups was observed for $\delta$-tocopherol concentration, but in thigh meat the concentration of $\delta$-tocopherol was lower in groups RFE and RFES than in the control and RF groups $(P \leq 0.05)$. 
Table 7. Concentration of tocopherols $\left(\mu \mathrm{g} \cdot \mathrm{g}^{-1}\right)$, cholesterol and 25-OH-cholesterol (mg $100 \mathrm{~g}^{-1}$ ) in vacuum-packed samples of chicken breast and thigh meat after 3 months of frozen storage

\begin{tabular}{|c|c|c|c|c|c|}
\hline \multirow{2}{*}{ Indices } & \multicolumn{4}{|c|}{ Dietary treatments } & \multirow{2}{*}{ SEM } \\
\hline & control & $\mathrm{RF}$ & RFE & RFES & \\
\hline \multicolumn{6}{|l|}{ Breast meat, $\mathrm{mg} \cdot \mathrm{g}^{-1}$} \\
\hline$\delta$ - tocopherol & 2.55 & 3.93 & 3.07 & 3.62 & 0.432 \\
\hline$y$ - tocopherol & $0.08^{\mathrm{a}}$ & $0.29^{b}$ & $0.48^{c}$ & $0.37^{\mathrm{bc}}$ & 0.041 \\
\hline a- tocopherol & $8.10^{\mathrm{a}}$ & $8.50^{\mathrm{a}}$ & $14.07^{b}$ & $13.13^{b}$ & 1.283 \\
\hline a- tocopherol acetate & $11.45^{\mathrm{a}}$ & $27.16^{b}$ & $20.17^{a b}$ & $20.13^{a b}$ & 3.214 \\
\hline cholesterol & $22.2^{\mathrm{a}}$ & $66.4^{\mathrm{b}}$ & $60.3^{b}$ & $70.6^{b}$ & 4.380 \\
\hline 25-OH-cholesterol & 3.76 & 2.98 & 2.83 & 2.35 & 0.384 \\
\hline \multicolumn{6}{|l|}{ Thigh meat } \\
\hline$\delta$ - tocopherol & $6.13^{b}$ & $6.09^{b}$ & $4.39^{\mathrm{a}}$ & $4.47^{\mathrm{a}}$ & 0.433 \\
\hline$y$ - tocopherol & $0.37^{\mathrm{b}}$ & $0.08^{\mathrm{a}}$ & $0.39^{b}$ & $0.39^{b}$ & 0.039 \\
\hline a- tocopherol & $8.99^{a}$ & $8.71^{a}$ & $14.50^{b}$ & $13.36^{b}$ & 1.340 \\
\hline a- tocopherol acetate & $39.76^{b}$ & $41.73^{b}$ & $30.64^{a}$ & $28.69^{a}$ & 2.118 \\
\hline cholesterol & $62.4^{a}$ & $86.3^{b}$ & $83.3^{b}$ & $82.4^{b}$ & 3.560 \\
\hline 25-OH-cholesterol & 2.50 & 3.92 & 3.21 & 3.55 & 0.395 \\
\hline
\end{tabular}

control, RF, RFE, RFES see Table 1 ; ${ }^{\text {ab }}$ means with different superscipts within a row are significantly different at $P \leq 0.05$

The concentration of $\alpha$-tocopherol acetate in breast meat was significantly higher in group RF in comparison with the control $(P \leq 0.05)$. The concentration of this vitamin in thigh meat was similar in the control and RF groups, but significantly lower in groups RFE and RFES $(P<0.05)$. The cholesterol content in both breast and thigh meat was lower in the control group, higher in groups RF, RFE and RFES. Dietary treatments did not change the concentration of 25-OH-cholesterol in meat after 3 months of storage.

The concentration of TBARS in samples of breast and thigh meat after 3 weeks or 3 months of frozen storage is shown in Table 8. After 3 weeks of storage in a freezer, the concentration of TBARS in thigh and breast meat was, on average, $0.15 \mathrm{mg} \cdot \mathrm{kg}^{-1}$ and was slightly higher $\left(0.19 \mathrm{mg} \cdot \mathrm{kg}^{-1}\right)$ only in the breast meat of RF birds. After 3 months of frozen storage, the concentration of TBARS in meat significantly increased $(P<0.01)$, more in breast meat than in thigh meat. An interaction between experimental factors (storage time $\times$ treatment) was found for thigh meat $(P \leq 0.01)$. The increased n-3 PUFA content in the diet caused a higher TBARS concentration in thigh meat (control vs group RF), but addition of vitamin E restored it to the control level (RFE vs control). Also, vitamin E and Se supplementation led to lower TBARS concentrations in comparison with group RF, but they were still higher than in the control group (RFES vs control). On the other hand, after 3 months of frozen storage, the breast-meat TBARS concentration did not differ among groups.
Table 8. Main effects of dietary fat source, vitamin $E$ and selenium supplementation on TBARS concentration (mg of malondialdehyde/ $\mathrm{kg}$ ) in vacuum-packed samples of breast and thigh meat after 3 weeks or 3 months of frozen storage $(n=9)$

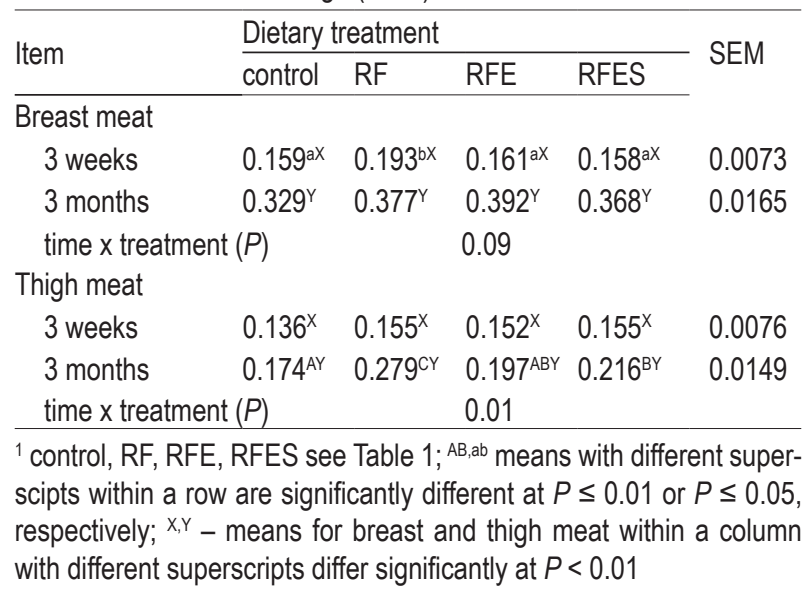

\section{Discussion}

The content of long-chain n-3 PUFA (the sum of EPA, DPA and DHA) in fish oils used in animal feeding varies from $6 \%$ to $41.3 \%$ of FA (Sauvant et al., 2004). The rendered fish oil used in the present study had a relatively low content of long-chain n-3 PUFA in comparison with the above values. However, the substitution of lard by rape seeds and fish oil enriched dietary lipids with $\alpha$-linolenic acid, EPA and DHA and substantially lowered the $n-6 / n-3$ PUFA ratio in the experimental diets.

The final body weight of chickens in the present study averaged $2.3 \mathrm{~kg}$ and was about $16 \%$ higher than the weight expected for broiler Ross 308 females at day 35 of life (Aviagen, 2012). The BWG of birds fed the diet with a modified n-6/n-3 PUFA ratio did not differ from the control, but it was lower by $2.6 \%$ in the group fed the diet with a high vitamin $E$ level and lower by $4 \%$ in the group with a high level of both vitamin E and Se. In the group with additional supplementation of both vitamin $E$ and Se, FCR was also significantly worse than in the remaining groups. These findings are in opposition to those of many authors, who reported that the modification of the dietary n-6/n-3 PUFA ratio with the use of plant oils and/or supplementation of diets with higher levels of vitamin $E$ or vitamin $E$ and Se is usually without consequences (Cortinas et al., 2004; Kim et al., 2010; Qi et al., 2010) or has positive effects on bird performance (Młodkowski et al., 2003; Koreleski and Świątkiewicz, 2006).

In the present study, the substitution of animal fat by fat from rape seeds and fish oil resulted in similar (in thigh meat) or slightly higher (in breast meat) levels of n-6 PUFA, but higher levels of n-3 PUFA, 
and substantially decreased the n-6/n-3 PUFA ratio in both kinds of meat. This supports the findings of many studies that the fatty acid profile of chicken meat depends on the dietary polyunsaturation level (Nguyen et al., 2003; Cortinas et al., 2004; Bou et al., 2005; Koreleski and Świątkiewicz, 2006; Jankowski et al., 2012). Increased dietary levels of vitamin $\mathrm{E}$ or both antioxidants in the diets with rape seeds and fish oil was associated with a lower n-6 PUFA content in breast and thigh meat and lower content of n-3 PUFA in thigh meat in comparison with group RF. The content of n-3 PUFA was higher only in the breast meat of chickens fed diets high in both vitamin $\mathrm{E}$ and Se. The effects of vitamin $\mathrm{E}$ and selenium on the fatty acid profile of chicken tissues are rather conflicting. It was argued that $\alpha$-tocopherol and Se may protect PUFA from oxidation, avoiding their loss, or may promote fatty acid synthesis by a positive effect on the activity of $\Delta 4-, \Delta 5-, \Delta 6-$ desaturases and elongases, enzymes involved in the processes leading to LC-PUFA formation (Infante, 1999). Some authors showed that dietary selenium did not influence LC-PUFA levels (Bou et al., 2005; Nyquist et al., 2013) in broiler meat. However, Haug et al. (2007) found more n-3 LC-PUFA in the thigh meat of broilers fed a diet with a high level of Se $\left(0.84 \mathrm{mg} \cdot \mathrm{kg}^{-1}\right)$ compared with a lower level of this element. Also Kralik et al. (2012) reported that the n-3 PUFA ratio in breast muscle increased when broiler diets were supplemented with Se. According to Surai and Sparks (2000), the proportion of n-3 PUFA in different chicken tissues was higher when the diet was supplemented with vitamin E. Other authors (Cortinas et al., 2004; Rymer and Givens, 2010) found no effect of supplementing broiler diets with vitamin $\mathrm{E}$ on the fatty acid profile of thigh and breast meat. In the current study, in birds fed rape seeds and fish oil the cholesterol content in breast and thigh meat was 65.8 and $84 \mathrm{mg} \cdot 100 \mathrm{~g}^{-1}$, respectively. Both values are very similar to the respective values $\left(65.6\right.$ and $\left.83.8 \mathrm{mg} \cdot 100 \mathrm{~g}^{-1}\right)$ given by Ajuyah et al. (1991), slightly lower than presented by Grau et al. (2001), and within the limits reported for broiler meat in the review by Dinh et al. (2011). The dietary level of vitamin $\mathrm{E}$ and Se affected neither cholesterol nor 25-OH-cholesterol contents in meat after 3 months frozen storage.

After supplementation of broiler diets with additional vitamin $\mathrm{E}$, the $\alpha$-tocopherol content in both breast and thigh meat increased. Similar results were presented by Młodkowski et al. (2003) and Koreleski and Świątkiewicz (2006). Feeding the diet supplemented with a higher level of vitamin E combined with excessive Se level had no effect on the $\alpha$-tocopherol concentration in meat, similarly as in the study by Taulescu et al. (2011).

The enrichment of chicken meat with n-3 PUFA may lead to deterioration of meat quality caused by lipid oxidation, called oxidative rancidity. It is responsible for unpleasant odours, loss of texture, consistency, appearance, and nutritional value of the meat (Perez et al., 2010; Jankowski et al., 2012). The thiobarbituric acid reactive substances (TBARS) test is a method often used for the detection of lipid oxidation in food. Frigg (1992) proposed an approximate scale for interpretation of TBARS values in meat (in mg MDA $\cdot \mathrm{kg}^{-1}$ ): $\leq 0.2$ good quality, $0.2-0.5$ tolerable, $0.5-1.5$ somewhat oxidized, 1.5-5 oxidized, $\geq 5$ rancid. According to this scale, in the present study after 3 weeks of frozen storage both the breast and thigh meat were good quality.

Oxidative processes during storage cannot be stopped, even in vacuum-packed meat, because they utilize the oxygen from tissue components. In the present study, after 3 months storage the TBARS concentration in breast and thigh meat was still in the tolerable level. In broilers fed the rape seeds and fish oil-containing diet, the TBARS concentration in thigh meat was higher compared with controls and declined with the enrichment of the diet with vitamin $\mathrm{E}$, with or without the additional dose of Se. Grau et al. (2001) and Koreleski and Świątkiewicz (2006) also reported that supplementation of broiler diets with vitamin $\mathrm{E}$ lowered TBARS values and cholesterol levels in meat after frozen storage. Bou et al. (2009) reviewed the results of many authors and concluded that $\alpha$-tocopherol added to poultry diets has a protective effect against lipid and cholesterol oxidation and positively affects the sensory characteristics of meat. The results obtained in our study indicate that $150 \mathrm{mg}$ vitamin $\mathrm{E}$ per $\mathrm{kg}$ diet would be sufficient to prevent oxidative processes in meat, but, similarly as Taulescu et al. (2011), we observed neither positive nor negative effects of simultaneously supplying vitamin E and Se in excess of requirements on the TBARS concentration in meat.

\section{Conclusions}

It may be concluded that broiler meat enriched with n-3 PUFA may be produced by feeding a diet containing rape seeds and fish oil during the last weeks before slaughter. Fortification of the diet with vitamin $\mathrm{E}$ increases its content in meat, as well as 
improves the oxidative stability of frozen stored meat, but no additional benefit was observed in simultaneously supplying vitamin E combined with Se in excess of requirements.

\section{Acknowledgements}

The study was realized within the project 'BIOFOOD - innovative, functional products of animal origin' No. POIG.01.01.02-014-090/09 co-financed by the European Union from the European Regional Development Fund within the Innovative Economy Operational Programme 2007-2013.

\section{References}

Ajuyah A.O., Lee K.H., Hardin R.T., Sim J.S., 1991. Influence of dietary full-fat seeds and oils on total lipid, cholesterol and fatty acid composition of broiler meats. Can. J. Anim. Sci. 71, 1011-1019

Aviagen, 2012. Ross 308 broiler: Performance objectives. en.aviagen. com/ross-308/

Bou R., Codony R., Tres A., Decker E.A., Guardiola F., 2009. Dietary strategies to improve nutritional value, oxidative stability, and sensory properties of poultry products. Crit. Rev. Food Sci. Nutr. 49, 800-822

Bou R., Guardiola F., Barroeta A.C., Codony R., 2005. Effect of dietary fat sources and zinc and selenium supplements on the composition and consumer acceptability of chicken meat. Poultry Sci. 84, 1129-1140

Czauderna M., Kowalczyk J., Korniluk K., Wąsowska I., 2007. Improved saponification then mild base- and acid-catalyzed methylation is a useful method for quantifying fatty acids, with special emphasis on conjugated dienes. Acta Chromatogr. 18, 59-71

Czauderna M., Kowalczyk J., Niedźwiedzka K.M., 2009. Simple HPLC analysis of tocopherols and cholesterol from specimens of animal origin. Chem. Anal. (Warsaw) 54, 203-214

Cortinas L., Villaverde C., Galobart J., Baucells M.D., Codony R., Barroeta A.C., 2004. Fatty acid content in chicken thigh and breast as affected by dietary polyunsaturation level. Poultry Sci. 83, 1155-1164

Dinh T.T.N., Thompson L.D., Galyean M.L., Brooks J.C., Patterson K.Y., Boylan L.M., 2011. Cholesterol content and methods for cholesterol determination in meat and poultry. Comp. Rev. Food Sci. Food Saf. 10, 269-289

Frigg M., 1992. Research experiences with vitamin E for poultry meat quality. In: Proceedings of the Roche Seminar on Poultry Meat Quality. XIX World's Poultry Congress. Amsterdam (The Netherlands), pp. 2

Grau A., Guardiola F., Grimpa S., Barroeta A.C., Codony R., 2001. Oxidative stability of dark chicken meat through frozen storage: Influence of dietary fat and a-tocopherol and ascorbic acid supplementation. Poultry Sci. 80, 1630-1642

Haug A., Eich-Greatorex S., Bernhoft A., Wold J.P., Hetland H., Christophersen O.A., Sogn T., 2007. Effect of dietary selenium and omega-3 fatty acids on muscle composition and quality in broilers. Lipids Health Dis. 6, 29, doi: 10.1186/1476-511X-6-29

Infante J.P., 1999. A function for the vitamin E metabolite a-tocopherol quinine as an essential enzyme cofactor for the mitochondrial fatty acid desaturases. FEBS Lett. 446, 1-5
Jankowski J., Zduńczyk Z., Mikulski D., Juśkiewicz J., Naczmański J., Pomianowski J.F., Zduńczyk P., 2012. Fatty acid profile, oxidative stability, and sensory properties of breast meat from turkeys fed diets with a different $n-6 / n-3$ PUFA ratio. Eur. J. Lipid Sci. Technol. 114, 1025-1035

Kim Y.J., Park W.Y., Choi I.H., 2010. Effects of dietary alpha-tocopherol, selenium, and their different combinations on growth performance and meat quality of broiler chickens. Poultry Sci. 89, 603-608

Konieczka P., Rozbicka-Wieczorek A.J., Więsyk E., Smulikowska S., Czauderna M., 2014. Improved derivatization of malondialdehyde with 2-thiobarbituric acid for evaluation of oxidative stress in selected tissues of chickens. J. Anim. Feed Sci. 23, 190-197

Koreleski J., Światkiewicz S., 2006. The influence of dietary fish oil and vitamin $E$ on the fatty acid profile and oxidative stability of frozen stored chicken breast meat. J. Anim. Feed Sci. 15, $631-640$

Kralik Z., Kralik G., Grčević M., Suchý P., Straková E., 2012. Effects of increased content of organic selenium in feed on the selenium content and fatty acid profile in broiler breast muscle. Acta Vet. Brno 81, 31-35

Młodkowski M., Światkiewicz S., Koreleski J., Kubicz. M., 2003. The effect of supplemental vitamin $E$ and dietary rapeseed oil level on broiler performance, meat and fat quality. J. Anim. Feed Sci. $12,121-132$

Nguyen C.V., Smulikowska S., Mieczkowska A., 2003. Effect of linseed and rapeseed or linseed and rapeseed oil on performance, slaughter yield and fatty acid deposition in edible parts of the carcass in broiler chickens. J. Anim. Feed Sci. 12, 271-288

Nyquist N.F., Rødbotten R., Thomassen M., Haug A., 2013. Chicken meat nutritional value when feeding red palm oil, palm oil or rendered animal fat in combinations with linseed oil, rapeseed oil and two levels of selenium. Lipids Health Dis. 12, 69, doi:10.1186/1476-511X-12-69

Olmedilla-Alonso B., Jiménez-Colmenero F., Sánchez-Muniz F.J., 2013. Development and assessment of healthy properties of meat and meat products designed as functional foods. Meat Sci. 95, 919-930

Perez T.I., Zuidhof M.J., Renema R.A., Curtis J.M., Ren Y., Betti M., 2010. Effects of vitamin $E$ and organic selenium on oxidative stability of $\omega-3$ enriched dark chicken meat during cooking. J. Food Sci. 75, T25-T34

Qi K.K., Chen J.L., Zhao G.P., Zheng M.Q., Wen J., 2010. Effect of dietary $\omega-6 / \omega-3$ on growth performance, carcass traits, meat quality and fatty acid profiles of Beijing-you chicken. J. Anim. Physiol. Anim. Nutr. 94, 474-485

Rymer C., Givens D.I., 2010. Effects of vitamin E and fish oil inclusion in broiler diets on meat fatty acid composition and on the flavour of a composite sample of breast meat. J. Sci. Food Agric. 90, 1628-1633

Sauvant D., Perez J.-M., Tran G. (Editors), 2004. Tables of Composition and Nutritional Value of Feed Materials. Wageningen Academic Publishers (The Netherlands) and INRA, Paris (France)

Smulikowska S., Rutkowski A. (Editors), 2005. Recommended Allowances and Nutritive Value of Feedstuffs. Poultry Feeding Standards (in Polish). $4^{\text {th }}$ Edition. The Kielanowski Institute of Animal Physiology and Nutrition, PAS, Jabłonna (Poland) and PB of WPSA

Surai P.F., Sparks N.H.C., 2000. Tissue-specific fatty acid and a-tocopherol profiles in male chickens depending on dietary tuna oil and vitamin E provision. Poultry Sci. 79, 1132-1142

Taulescu C., Mihaiu M., Bele C., Matea C., Dan S.D., Mihaiu R., Lapusan A., 2011. Antioxidant effect of vitamin $E$ and selenium on omega-3 enriched poultry meat. Bull. Univ. Agr. Sci. Vet. Med. Vet. Med. 68, 293-299 